\title{
Chest Pain on Exertion: Origin of the Right Coronary Artery from the Left Coronary Sinus, through the Aortic Pulmonary Sulcus with Squeezed, or Anterior Descending Branch Borderline Coronary Lesion?
}

\author{
Jun Luo, Zhihong Zhao*, Chan Jin, Xinming $\mathbf{L i}^{*}$ \\ Department of Cardiology, ZhouPu Hospital, Shanghai, China \\ Email: ${ }^{*}$ zhihong_zhao@126.com, ${ }^{*}$ xinmingli6@126.com
}

Received 7 March 2015; accepted 21 April 2015; published 24 April 2015

Copyright (C) 2015 by authors and Scientific Research Publishing Inc.

This work is licensed under the Creative Commons Attribution International License (CC BY). http://creativecommons.org/licenses/by/4.0/

(c) () Open Access

\begin{abstract}
The prognosis of patients in whom the right coronary artery (RCA) arises from the left coronary sinus (LCS) is unequal. An initial intramural course of the coronary artery within the aortic media is considered to cause myocardial ischemia in cases of coronary anomalies. In this case report, we present one patient admitted due to chest pain on exertion that suggested angina. Her only risk factor for coronary artery disease was hypertension. Clinical examination findings that the origin of the right coronary artery from the LCS, through the aortic pulmonary sulcus with atherosclerotic narrowing and squeezed of the RCA critical ostial, stenosis at the ostium of the RCA and the middle of left anterior descending (LAD) coronary, intravascular ultrasonography (IVUS) showed LAD and RCA minimal lumen area were $3.9 \mathrm{~mm}^{2}, 5.9 \mathrm{~mm}^{2}$; plaque burden $66 \%, 65 \%$ respectively. We inserted EXCEL $3.0 \times 18 \mathrm{~mm}$ stent in LAD stenosis. No complaints and adverse events were noticed during a 1-year follow-up.
\end{abstract}

\section{Keywords}

Anomalous Right Coronary Artery, Left Sinus of Valsalva, Intravascular Ultrasonography

\footnotetext{
${ }^{*}$ Corresponding authors.
} 


\section{Introduction}

Coronary anomalies are among the known causes of sudden death [1]. An anomalous origin of the right coronary artery from the left sinus of valsalva (ARCA) has been reported in 6\% - 27\% of patients with coronary anomalies. ARCA is known to cause intermittent ischemia, myocardial infarction, and sudden death [2] [3]. The accepted therapy for individuals with symptoms or evidence of exercise-induced myocardial ischemia is coronary interventional therapy and surgery. Surgical options include unroofing of the intramural portion of the aberrant artery, reimplantation of the ostium into the appropriate sinus, and coronary artery bypass grafting (CABG) [4] [5]. We describe our experience with a patient with ARCA who accompanied with LAD borderline stenosis.

\section{Case Report}

A 52-year-old female presented with chest pain on exertion that suggested angina. Her only risk factor for coronary artery disease was hypertension. She had not experienced chest trauma or thoracic surgery. It was clinically negative, but electrocardiography was positive. Echocardiography demonstrated no structural heart disease with a normal left ventricular ejection fraction. Cardiac computed tomography and 3-dimensional reconstruction imaging revealed an anomalous origin of the RCA from the left sinus of Valsalva, through the aortic pulmonary sulcus. The initial 5-mm part of the artery was found to course intramurally in the wall of the aorta, and critical ostial stenosis was suspected (Figure 1(a), Figure 1(b)). Therefore, conventional coronary angiography was performed. It confirmed coronary anomaly and demonstrated a borderline (60\% - 70\%) stenosis at the ostium of the RCA and the middle of left anterior descending (LAD) coronary (Figure 1(c), Figure 1(d)). IVUS analysis was performed according to "Tissue Characterisation Using Intravascular Radiofrequency Data Analysis: Recommendations for Acquisition, Analysis, Interpretation and Reporting.” [6], distal to the minimal lumen area (MLA) site in LAD were $3.9 \mathrm{~mm}^{2}$, and plaque burden $66 \%$. the middle of the vessel area in RCA were $20 \mathrm{~mm}^{2}$, the compression is conspicuous at the ostium, the opening is irregular, and MLA were $5.9 \mathrm{~mm}^{2}$, and plaque burden 65\% (Figure 1(e)). After heart team consultation, we decided to treat the patient with LAD percutaneous intervention. We dilated the mid-LAD narrowing with percutaneous transcatheter coronary artery ballooning and stenting, and EXCEL $3.0 \times 18 \mathrm{~mm}$ stent inserted (Figure 1(f)). No complaints and adverse events were noticed during a 1-year follow-up.

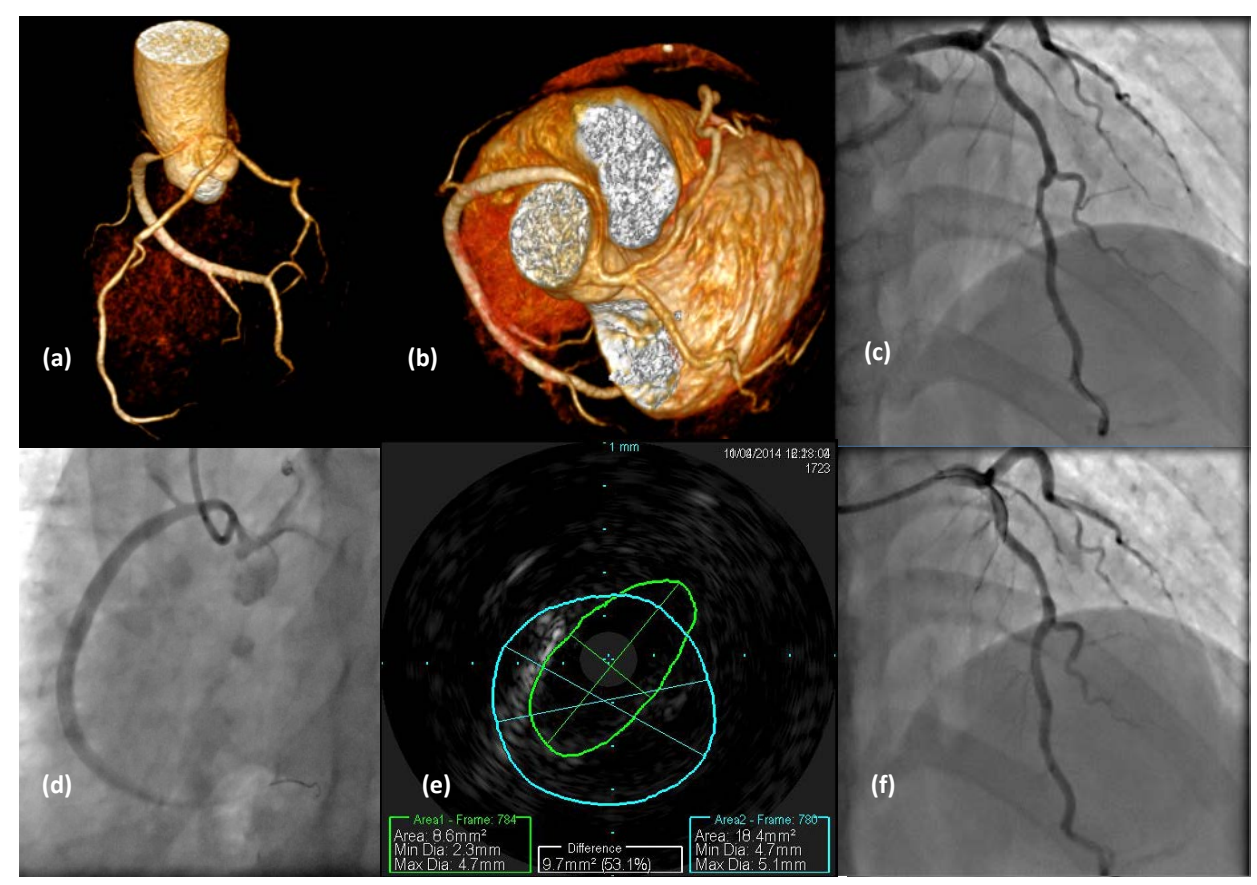

Figure 1. (a), (b) computed tomography: RCA originating intramurally from the left sinus of Valsalva; (c), (d) coronary angiography of the left coronary artery (LCA) and right coronary artery (RCA); (e) ostium of the RCA examined by VH-IVUS. 


\section{Discussion}

Coronary arteries of anomalous origin are uncommon and nencountered in $0.2 \%-1.2 \%$ of patients undergoing percutaneous coronary intervention (PCI) and represent a marked deviation of the normal anatomic pattern [7] [8]. ARCA from the left sinus of valsalva has been reported in $6 \%-27 \%$ of patients with coronary anomalies [1]. ARCA has also been documented to originate from the pulmonary artery, left ventricular outflow tract, left main coronary artery, aorto-left ventricular canal, non coronary sinus of valsalva and from above the sinus of valsalva [9] [10].

The management of patients with ARCA is controversial [11]. Traditionally, the surgical approach for ARCA has involved a full sternotomy and the use of cardiopulmonary bypass. Now the ARCA who were operated upon using a small right anterior thoracotomy incision to perform a right internal mammary artery to RCA bypass with ligation of the proximal RCA. This was performed under direct vision and without cardiopulmonary bypass [4] [12]. Also the unusual location and course of the ARCA anomaly poses a technical challenge for the interventionalist, PCI of ARCA requires appropriate guide catheter selection according to the anatomy of origin for successful cannulation and to reduce the contrast usage and radiation exposure [5].

In adults, because of the reduced risk of sudden death with age, CABG or PCI is recommended only for patients with symptoms or for those who have demonstrable ischemia on exercise testing even in the absence of symptoms. In some cases, sudden death may be asymptomatic, and it has occurred in patients who had a prior negative exercise-stress test. For the older patients, whether it's necessary to deal with all the ARCA patients with PCI or CABG is still in controversy. Our patients, no symptom before, IVUS found that LAD maybe the culprit vessel which caused chest pain, so the stent were implanted. The stenosis at the ostium of the RCA examined by IVUS found that even through compress accompanied with plaque burden were 65\%, but MLA were $5.9 \mathrm{~mm}^{2}$, which can assurance the blood supply.

\section{Conclusion}

ARCA can choose conservative treatment in older patient in the absence of symptoms, and IVUS proved the squeeze not influence the blood supply.

\section{Funding}

Financial support from the ZhouPu Hospital Medical Foundations is gratefully acknowledged.

\section{Conflicts of Interest}

All authors have none to declare.

\section{References}

[1] Camarda, J. and Berger, S. (2012) Coronary Artery Abnormalities and Sudden Cardiac Death. Pediatric Cardiology, 33, 434-438. http://dx.doi.org/10.1007/s00246-012-0168-0

[2] Passaseo, I., Cacciotti, L., Camastra, G.S., Favoccia, C., Pauselli, L., et al. (2014) Anomalous Origin of the Right Coronary Artery from the Left Sinus of Valsalva: Essential Role of Computed Tomography to Clarify the Coronary Artery Course and Literature Review on Diagnostic and Therapeutic Management in 215 Cases. Giornale Italiano di Cardiologia, 15, 189-195.

[3] Fineschi, V., Maresi, E., Di Padua, M., Riezzo, I. and Neri, M. (2006) Sudden Cardiac Death Due to Anomalous Origin of the Right Coronary Artery: A Case Report in a Child. International Journal of Cardiology, 108, 426-428. http://dx.doi.org/10.1016/j.ijcard.2005.03.076

[4] Reddy, R.C., Takahashi, M., Beckles, D.L. and Filsoufi, F. (2012) Anomalous Right Coronary Artery from the Left Sinus: A Minimally Invasive Approach. European Journal of Cardio-Thoracic Surgery: Official Journal of the European Association for Cardio-Thoracic Surgery, 41, 287-290.

[5] Uthayakumaran, K., Subban, V., Lakshmanan, A., Pakshirajan, B., Solirajaram, R., et al. (2014) Coronary Intervention in Anomalous Origin of the Right Coronary Artery (ARCA) from the Left Sinus of Valsalva (LSOV): A Single Center Experience. Indian Heart Journal, 66, 430-434. http://dx.doi.org/10.1016/j.ihj.2014.05.029

[6] Garcia-Garcia, H.M., Mintz, G.S., Lerman, A., Vince, D.G., Margolis, M.P., et al. (2009) Tissue Characterisation Using Intravascular Radiofrequency Data Analysis: Recommendations for Acquisition, Analysis, Interpretation and Re- 
porting. EuroIntervention: Journal of EuroPCR in Collaboration with the Working Group on Interventional Cardiology of the European Society of Cardiology, 5, 177-189. http://dx.doi.org/10.4244/EIJV5I2A29

[7] Click, R.L., Holmes Jr., D.R., Vlietstra, R.E., Kosinski, A.S. and Kronmal, R.A. (1989) Anomalous Coronary Arteries: Location, Degree of Atherosclerosis and Effect on Survival-A Report from the Coronary Artery Surgery Study. Journal of the American College of Cardiology, 13, 531-537. http://dx.doi.org/10.1016/0735-1097(89)90588-3

[8] Bagmanova, Z.A. (2010) Anomalies of Coronary Arteries. Kardiologiia, 50, 48-55.

[9] Kawamura, A., Oshima, Y., Maruo, A. and Matsuhisa, H. (2012) Compression of an Anomalous Single Coronary Artery from Pulmonary Artery by Banding. European Journal of Cardio-Thoracic Surgery: Official Journal of the European Association for Cardio-Thoracic Surgery, 41, e59-e61.

[10] Bhatia, S.R. and English, R.F. (2012) Anomalous Right Coronary Artery Arising from the Pulmonary Artery: Case Report and Review of Literature. Cardiology in the Young, 22, 346-348. http://dx.doi.org/10.1017/S1047951111001351

[11] Skrzypek, A., Gackowski, A., Szot, W., Banys, R., Nessler, J., et al. (2014) Anomalous Origin and Interarterial Course of the Right Coronary Artery: Diagnostic and Therapeutic Dilemmas. Polskie Archiwum Medycyny Wewnetrznej, 124, 746-747.

[12] Cho, S.H., Joo, H.C., Yoo, K.J. and Youn, Y.N. (2014) Anomalous Origin of Right Coronary Artery from Left Coronary Sinus: Surgical Management and Clinical Result. The Thoracic and Cardiovascular Surgeon. http://dx.doi.org/10.1055/s-0034-1376256 